\title{
An integrated model of system dynamics and fuzzy cognitive mapping approach for waste management in Turkey
}

\author{
Konyalioğlu A.K.* and Bereketli Zafeirakopoulos I. \\ Department of Industrial Engineering, Galatasaray University, Istanbul, Turkey \\ Received: 31/01/2019, Accepted: 30/07/2019, Available online: 22/10/2019 \\ *to whom all correspondence should be addressed: e-mail: konyalioglua@itu.edu.tr \\ https://doi.org/10.30955/gnj.003041
}

\begin{abstract}
Waste management is one of the most crucial topics of the sustainability concept. In Turkey, waste management of the small household appliances under waste of electrical and electronic equipment (WEEE) category still remains as an issue to handle although its production is very large and long-established. The main reason is that many of the household appliances' wastes are not properly treated in waste management process despite the fact that Turkey has recovery and collection targets. This outboard of wastes non-treated in an environmentally friendly way, such as recycling or reuse, gives rise to environmental damage. The aim of this paper is to integrate a system dynamics and fuzzy cognitive mapping model in order to evaluate and develop recovery options of small household appliances' wastes which are not treated according to the regulations in Turkey. The first part of the proposed model is to build a system dynamics model by developing recovery options for small household appliances' waste management while the second part is to evaluate the relations between supporting factors of recovery options by using Fuzzy Cognitive Mapping.
\end{abstract}

Keywords: WEEE, fuzzy cognitive mapping, system dynamics, small household appliances, waste management.

\section{Introduction}

Waste Electrical and Electronic Equipment (WEEE), also called as e-waste, is one of the most crucial and rapidly growing issues in the world based on international trends. The waste amount, including typical wastes and EEE wastes, continues to increase as a result of the growth in population, and the over production and consumption (Takiguchi, 2016). It is stated that European Union generates e-waste even faster, at a rate of 3-5\% per year, compared to other solid wastes (Pariatamby and Victor, 2013).

WEEE can be defined as an electrically operated device that no longer satisfies the user or manufacturer for a specific purpose (Sinha-Khetriwal et al., 2005). The possible treatment ways of WEEE are reuse, recycling, landfill, incineration with energy recovery, etc. However most of the time companies do not follow those treatments and seek the low-cost and non-suitable ways of getting rid of their waste. Generally, e-wastes which are not reusable/recyclable, are mixed with reusable/ recyclable e-wastes in order to be sent to the least developed countries despite the fact that international laws and regulations do not allow mixing e-waste, which is moved internationally. This is both an illegal and non-environmental action. Therefore, it is crucial to apply the waste treatment policies defined by the regulations.

Electrical and electronic equipment sales are increasing day by day following to the popular technological trends in Turkey. High amount of sales means decreases in raw materials and increase in the waste amount, where both cases threaten the environment directly. Environmental directions for EEE are published in Turkey in 2012 to avoid harm to the environment by encouraging recovery options such as recycling or reusing of WEEE (URL1). According to the regulation, companies which are the main actors at the WEEE management factor, should get approval from the Government, directly from the Ministry of Environment and Urbanization, in order to conduct those waste's recovery and transportation activities (URL2). The ministry gives license for collecting, separating and reusing/recycling those e-wastes according to their categories (Öztürk, 2015). At the regulation, WEEE is classified under different categories and one of them is small household appliances produced by white goods manufacturers.

The aim of the study is to propose an integrated system dynamics and fuzzy cognitive mapping approach for minimizing the waste of small household appliances produced in Turkey that are sent to landfill areas without recycling, and to understand the relationship between factors, modelled using system dynamics, via Fuzzy Cognitive Mapping approach.

System dynamics helps us understanding a system and improving its operations management. System dynamics modelling is widely used in the literature for simulation purposes in different sectors and working fields. In the production area, system dynamics is used by Greasley to 
provide a discrete-event simulation method (2005). Lee et al. proposed a system dynamics approach based on functional dynamics to evaluate product-service systems (2015). Botha et al. used system dynamics modeling to compare three inventory management methods for theoretical and actual, daily data set by comparing the parameters of stock target settings (2017). In the field of finance management, Nair and Rodrigues explained financial parameters during production expansion by using system dynamics (2013). On the other hand, in management area, Barnabè suggested a balanced scorecard method based on system dynamics to evaluate strategic decision making (2011). In the education field, Pedamallu et al. (2010) applied a system dynamics model to evaluate educational infrastructure based on the quality of primary school of a developing country. In health area, Devi et al. (2010) studied system dynamics modeling for the waiting list of corneal transplants patients, and Al-Khatib et al. suggested a more understandable and sophisticated simulation method for hospital waste management by using system dynamics model (2016). Aside from many areas, system dynamics models can be proposed about WEEE as well. Ghisolfi et al. presented a system dynamics model to investigate legal bargaining power and incentives for the waste pickers of desktops and laptops measured by the volume of wastes (2016) however there are no studies in the literature about the WEEE management regulations and recovery target levels.

Fuzzy cognitive maps (FCMs) are graphical explanations for causal relationships given by Kosko in 1986. FCMs are preferred as a simulation methodology in terms of flexibility and fuzzy reasoning and also abstraction (Parsopoulos et al., 2003). As simplicity of modelling and easiness of the methodology FCMs have several advantages to be used. FCM models are being used in different study areas such as military, history, medicine, engineering, etc. (Stach et al., 2005)

There are only a few studies in literature which used FCMs in waste management (Buruzs et al., 2014; Hatwagner et al., 2014; Papageorgiou et al., 2017) however none of them is applied on WEEE management.

There exist studies about WEEE in Turkey but again, there is none focusing on waste management of small household appliances by using a system dynamics and fuzzy cognitive mapping models. This study will fill the gaps in the literature, and facilitate the understanding of the concept of environmental sustainability and related factors of small household appliances waste management in Turkey.

\section{Materials and methods}

\subsection{System dynamics modelling}

As a definition, system dynamics makes possible to understand and improve system thinking and operations management systems. Forrester (1994) studied system dynamics to develop a new perspective for system concept and production management. The first consideration is to cope up with real life cases consequently. The mathematical approach of the system, the system behavior due to time changes, consideration of other scenarios, and selection of the best technique constitute the system dynamics all together. The input data for this study's system dynamics model is Turkey's targets for recovery options and the small household appliance amount. The main aim of this model is increasing recovery options preference, such as recycling or reusing, in case of WEEE management. AnyLogic, a simulation software, is used to conduct this system dynamics model with zero error (URL4).

In order to observe the system behavior in our study, we need to model the system including the whole supply chain operations. The first part of the supply chain is the supply of the raw materials' starting the manufacturing operations. For this model, three suppliers are selected as an example. These suppliers are shown by "stock variables", which is a presentation form at the system dynamics model. As for defining the production process in the model, the real data was insufficient so that the total amount of small household appliances sold in Turkey and target values of the current regulation are considered. To reach the customer, three sub-distributors are connected under the main distributor. Finally for the waste generation, it is considered that customers might give up on their appliances when they are old or if they are broken down. The waste is collected either at municipality's facilities or collection centers. It is also important to create public awareness for the waste management via municipality's campaigns.

In this model, there are three additional effects that are used. These effects are assumed as constant numbers, and while running the model, it is seen that they have a positive and enhancing effect on waste collection amount and recovery options.

These effects are explained as follows:

1. Campaign Effect: This effect reflects the "bring the old equipment and take the new one with a reduction" situation, which means that consumers can pay a lower price for a new appliance. From the producers' point of view, it means reaching the governmental target by collecting appliances directly from the consumers.

2. Company Effect: This is the effect that provides the company, government support if they encourage recycling and recycling centers.

3. Municipality Campaign Effect: Consumers sometimes do not prefer to bring their old small household appliances to companies or private recycling centers. In other words, they can bring their appliances to municipality recycling centers. Municipalities can create public awareness with campaigns about environmental protection.

The system dynamics simulation using stock variables, which indicate the place or item being accumulated and Production flow which expresses the change in the stock variable, can be seen in the Figure 1. 


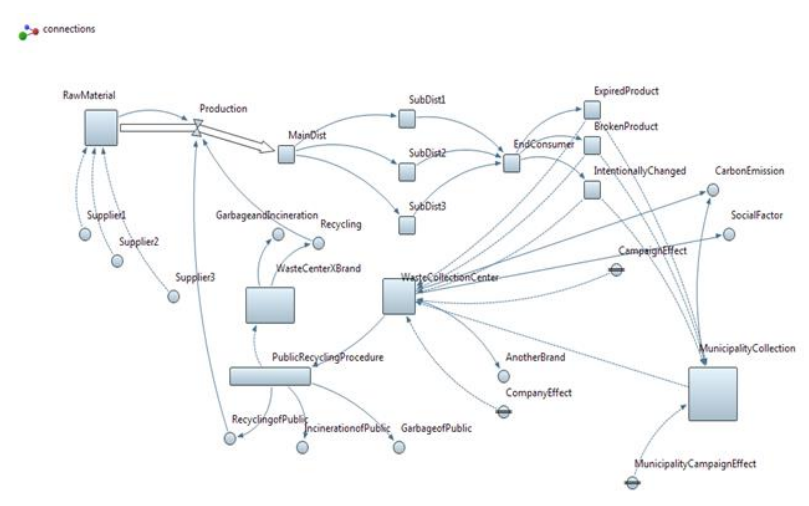

Figure 1. System dynamics model of small household appliances' waste management in Turkey (Konyalıoğlu \& Bereketli Zafeirakopoulos, 2018)

\subsection{Fuzzy cognitive mapping}

Fuzzy cognitive mapping is a very useful approach to evaluate and interpret the relationship between the factors. The connections interpreted between the factors explain the cognitive models under a system (Çoban et al., 2006). Cognitive maps generally include two main parts which are casual beliefs and concepts. Relationship between the variables may be negative or positive which indicates the direction of the change of the effect on the variable (Leon et al., 2014). The concept of fuzzy cognitive maps is similar to neural networks (NN). One may conclude that the factor's outputs are working as neurons.

To introduce fuzzy cognitive map (FCM), the first step is to decide the relations between factors as well as the arrows in directions. Fuzzy cognitive maps are like graphs which all have their adjacent matrices indicated as W.

The adjacent matrix of the FCM indicates the effecting factors between the variables. There exist three main types of variables which are transmitter, receiver and ordinary variables in FCM and these variable types can be explained in terms of outdegree (od) and indegree (id) values. The definitions can respectively be given as the outdegree (od) which is the sum of rows of a variable $\left(v_{i}\right)$ and the indegree value which is the sum of columns of $a$ variable $\left(v_{i}\right)$, and it indicates respectively the power of leaving and coming variable $a_{i j}$ by remarking that the transmitter variables have to obtain a zero of outdegree (eq. 1) and indegree (eq. 2). Transmitter variables can have a positive outdegree while receiver variables have a positive indegree. Ordinary variables can have either zero indegree or zero outdegree. Outdegree value represents the cumulative strength of connections, indicated as $a_{i j}$, of the leaving variable while indegree value expresses the strength of entering variables, given that there exist a total number of $\mathrm{N}$ variables (Ozesmi and Ozesmi, 2004).

$$
\begin{aligned}
& \operatorname{od}\left(v_{i}\right)=\sum_{k-1}^{N} \overline{a_{i i}} \\
& i d\left(v_{i}\right)=\sum_{k-1}^{N} \overline{a_{k i}}
\end{aligned}
$$

The value of each factor/concept is affected by the factors which are connected with weights and the previous value. An FCM includes nodes or concepts, donated as $C_{i}$, $\mathrm{I}=1,2,3 \ldots \mathrm{N}$, where $\mathrm{N}$ is the total number of nodes $C_{i}$. Generally a concept or node is defined as a constraint or driver (Kok, 2009). The values given in the equation 3 indicate that $A_{i+1}$ values can be defined as the activation level of the concept/node $C_{i}$ at the time i and the $W_{j i}$ are the weights of the interconnection from the concept $C_{i}$ at time step $\mathrm{t}$ to the concept $C_{j}$. Also, $W_{i j}$ measures the strength of the casual linkage from the node $C_{i}$ to the node $C_{j}$. In FCM, the direction of causality expresses if the node $C_{i}$ causes the node $C_{j}$ (Papageorgiou and Kontogianni, 2012)

$W_{i j}$ can have different values according to the causality situations.

- If $W_{i j}>0$, there is a positive causality between the nodes $C_{i}$ and $C_{j}$, which means an increase in the node $C_{i}$ causes an increase in the node $C_{j}$.

- If $W_{i j}<0$, there is a negative causality between the nodes $C_{i}$ and $C_{j}$, which means an increase in the node $C_{i}$ causes a decrease in the node $C_{j}$.

- If $W_{i j}=0$, there is not any causality between the nodes $C_{i}$ and $C_{j}$

- Connections or linkages between concepts $C_{i+1}$ and $C_{i}$ define the influence from the concept $C_{i}$ to the concept $C_{i+1}$. Each concept is just based on the influence of interrelated concept (Stylios and Groumpos, 2004)

$$
A_{i+1}=f\left(\sum_{\substack{j=1 \\ j \neq i}}^{n}\left[A_{i} \times W_{j i}\right]\right)
$$

The function $f$ is a nonlinear function (eq. 4) which is called as Sigmoid and given by (Han and Morag, 1995). This function is used to transform the evaluations given by experts into the crisp values in order to build the matrix $A$.

$$
f(x)=\frac{1}{1+e^{-x}}
$$

Implementing fuzzy cognitive mapping is supposed to be a very complex process as there are a lot of connections between the factors. In the study, the factors have been evaluated negatively or positively by the results of the simulation and the relations between the factors affecting waste collection and recovery options have been attributed.

Based on system dynamics modelling given in the Figure 1, the relationship between stock variables, campaign effects, production process and waste collection centers are evaluated by using Fuzzy Cognitive Mappings. In this study, fuzzy cognitive mapping approach enlightens the relationships between the factors affecting recovery options and waste recycling. The effect ratios are taken from system dynamics simulation according to the ratio at the first 10 years and the last 10 years. The ratios of the 
first 10 years and the last 10 years are the ratios coming from changes unit by unit of stocks and flows. The data has been gathered starting from 2008, however the study has been conducted in 2018. The study covers 65 years for simulation, and according the system dynamics simulation results it reaches the target level after the 55th year. The simulation ratios enable the $A$ matrix in the fuzzy cognitive mapping to be built. On the other hand, the ratios, in which key variables affect factors, have been used by using differentials in the simulation.

\section{Results}

\subsection{System dynamics model for the waste management of small household appliances}

The target of $50 \%$ of small household appliance waste to be recycled by 2018 was published in 2012 in the Turkish official gazette (URL3). The model in this study is conducted according to this target value. As a result, the $50 \%$ of the total amount of old, broken down or intentionally changed goods ends up with the recycling process in the model. There are two collection centers, named municipality and waste. The municipality collection target differs by the city size defined at the official gazette (2012).

The way to collect waste through municipalities is to increase the campaign effect. This is a positive action for reaching the target. In the simulation, based on the waste collection policy of Turkey, municipalities can use a campaign to increase public awareness for bringing expired, broken-down or changed small household appliances to municipalities' recycling centers. In this model, this campaign effect is used as a motivating and positive factor affecting municipality collection amounts.

Generally, all appliances are collected in waste collection centers in the model. The quantity of small household appliances gone into waste centers is assumed according to the target of $50 \%$ and proportionally, expired, broken or changed products are distributed accordingly. In Turkey, some electronic equipment companies have their own recycling centers. However, only one of these companies is put in the model as representative. Government or municipalities can sell the products to be recycled to electronic companies and these companies can use campaigns to attract appliances to their recycling centers. Companies can use these appliances in favor of their own companies or sell to public or governments after or during recycling process. As indicated in the model, appliances recycled by government or companies can directly go into production processes. On the other hand, the rest of appliances which is not recycled, named as garbage, cannot be in the production process again. They can be incinerated or landfilled, not reused. In this case, government and companies can make campaigns to create public awareness. In Turkey, some companies exchange old appliances with new ones, in order to recycle them.

There is a positive relation between produced goods and waste as shown in Figure 2. The raw material was a dynamic variable in the model so that the production amount can be decreased by time. As a result, waste amount also changes according to the demand fluctuation. The result of the 65 years simulation of the model is seen in Figure 2.

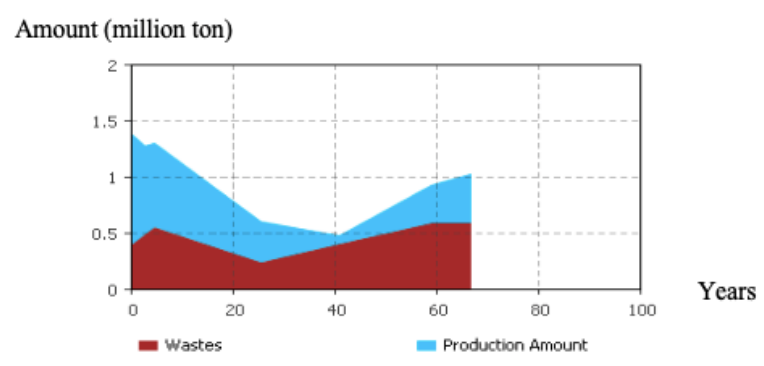

Figure 2. The relationship between wastes and production amounts in million ton/years (Konyalıoğlu and Bereketli Zafeirakopoulos, 2018)

Furthermore, Figure 3, obtained from simulation, shows the decrease of disposal while there is an increase in the recycling amount of waste. This decrease of disposal is the result of high campaign effect, the awareness of the people. Totally four effects, with constant values, are represented in this model to show the increase in recovery options as a result of them. Landfill and incineration rate over production decreases and production increases over time given that campaign and company effects are enlarged.

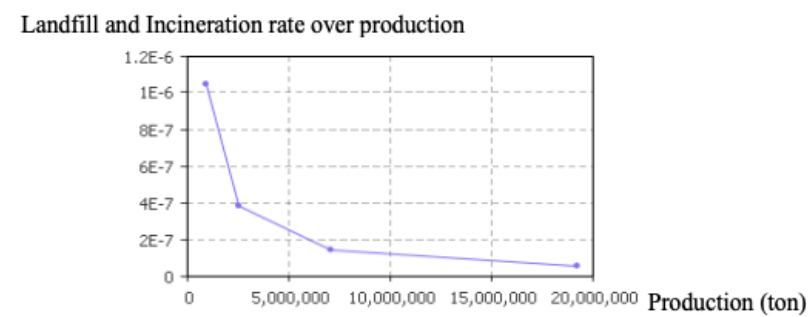

Figure 3. Relationship between recycling and IncinerationLandfill Rate in rate/ton (Konyalıoğlu and Bereketli Zafeirakopoulos, 2018)

After the simulation, it is also understood that the total incineration-landfill rate over total production decreases while production rate is increasing, as a result of the fact that recycled small household appliances go through production process while simulation has been run for 65 years.

\subsection{Fuzzy cognitive mapping approach for the evaluation of factors}

After the simulation given in the Figure 1, a fuzzy cognitive mapping has been built based on the simulation. The effecting values which may change the simulation results are evaluated by using Fuzzy Cognitive Mapping. Furthermore, key variables of the system dynamics simulation have been put in the FCM modelling in order to see which variable of the simulation is the center and affects the simulation more than other key variables. Fuzzy Cognitive Mapping given in the Figure 4 shows the 
relationships between the factors which have also been indicated in the simulation. The relationships, negative or positive, can be seen in the matrix $A$. The study mainly focuses on if the public or private recycling policies are better for minimizing landfill and incineration, and maximizing recovery options. By applying FCM modelling, the question is to decide which public or private recycling policies, and campaign effects, are more important than others, on the other hand which one is more effective for increasing recycling and recovery options. The blue arrows and red arrows show respectively positive and negative effects on the concepts. Furthermore, it is clearly seen that the complexity of the cognitive mapping leads us to a detailed analysis. The fuzzy cognitive mapping includes 41 connections which implies that the system is complex.

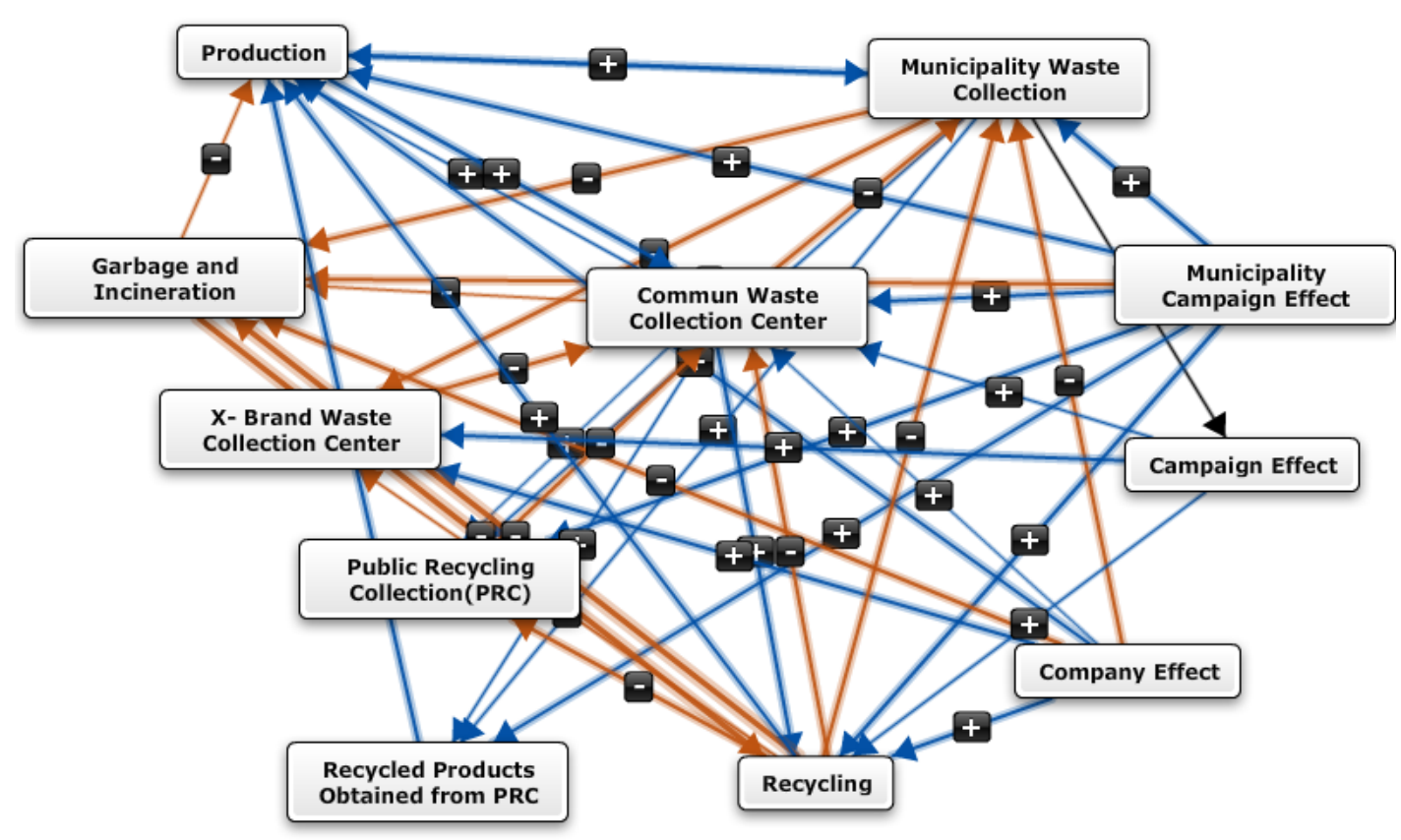

Figure 4. Fuzzy Cognitive Mapping for small household appliances' waste management

\begin{tabular}{|c|c|c|c|c|c|c|c|c|c|c|c|}
\hline Municipality Waste Collection & 0 & 0 & 0 & 0 & 0.12 & -0.2 & -0.3 & 0 & 0.12 & 0.14 & $0]$ \\
\hline Municipality Campaign Effect & 0.4 & 0 & 0.2 & 0 & 0.2 & 0 & -0.4 & 0.2 & 0.2 & 0.32 & 0 \\
\hline Common Waste Collection Center & -0.2 & 0 & 0 & 0 & 0.1 & 0 & -0.12 & 0.3 & 0.1 & 0.1 & 0 \\
\hline Company Effect & -0.2 & 0 & 0.1 & 0 & 0 & 0.4 & -0.2 & 0.2 & 0 & 0.2 & 0 \\
\hline Public Recycling Collection & 0 & 0 & -0.2 & 0 & 0 & 0 & 0 & 0 & 0 & 0 & 0 \\
\hline$A=X$ Brand Waste Collection Center & 0 & 0 & -0.18 & 0 & 0 & 0 & 0 & 0 & 0 & 0 & 0 \\
\hline Garbage and Incineration & 0 & 0 & 0 & 0 & 0 & 0 & 0 & -0.5 & 0 & -0.15 & 0 \\
\hline Recycling & -0.32 & 0 & -0.28 & 0 & -0.17 & -0.12 & -0.5 & 0 & 0 & 0.35 & 0 \\
\hline Recycled Products Obt. from PRC & 0 & 0 & 0 & 0 & 0 & 0 & 0 & 0 & 0 & 0.2 & 0 \\
\hline Production & 0.3 & 0 & 0.2 & 0 & 0 & 0 & 0 & 0 & 0 & 0 & 0 \\
\hline Campaign Effect & 0 & 0 & 0.15 & 0 & 0 & 0.3 & 0 & 0.15 & 0 & 0.15 & 0 \\
\hline
\end{tabular}

Furthermore, it can be seen in Table 1 that the municipality campaign effect has a greater centrality value than company effect that implies that for recycling, municipality campaign effect is more important factor in waste management of small household appliances. Municipality campaign effect that the municipality applies can be considered as the central of the model since it has the higher outdegree value as seen in the Table 1. Based on the adjacent matrix, it is said that several factors or concepts are directly connected with each other.
Company and campaign effects can be supportive factors for waste management of small household appliances in Turkey. Besides, based on the adjacent matrix and fuzzy cognitive mapping given in Figure 4 it can be seen that the recycling is the most affected by the Municipality Campaign Effect which implies that being a green and sustainable country is mostly possible when government policies are strictly applied. 
Table 1. Indegree, outdegree and centrality values of waste management components

\begin{tabular}{cccc}
\hline Component & Indegree & Outdegree & Centrality \\
\hline Municipality Waste Collection & 1.42 & 0.88 & 2.30 \\
\hline Municipality Campaign Effect & 0 & 1.8 & 1.8 \\
\hline Common Waste Collection Center & 1.31 & 0.92 & 2.23 \\
\hline Company Effect & 0 & 1.3 & 1.3 \\
\hline Public Recycling Collection (PRC) & 0.59 & 0.2 & 2.30 \\
\hline X Brand Waste Collection Center & 1.02 & 0.18 & 1.2 \\
\hline Landfill and Incineration & 1.52 & 0.65 & 2.17 \\
\hline Recycling & 1.35 & 1.74 & 3.09 \\
\hline Recycled Products Obtained from PRC & 0.42 & 0.2 & 0.62 \\
\hline Production & 1.34 & 0.5 & 1.84 \\
\hline Campaign Effect & 0 & 0.6 & 0.6
\end{tabular}

On the other hand, based on fuzzy cognitive mapping theory, as municipality campaign effect increases, directly the participation of recycled products of appliances in the system also increases. The company effect and campaign effect can increase production, which implies the participation of recycled products to the reproduction process, up to $15 \%$ while municipality campaign effect is able to increase up to $32 \%$. Production process is more affected by the municipality campaign effect and municipality waste collection.

\section{Conclusion and discussion}

In this study, a system dynamics and fuzzy cognitive mapping approach have been studied for small household appliances' waste management in Turkey. The system Dynamics model is run by using Anylogic simulation program while MentalModeler software is used for fuzzy cognitive mapping. The study mainly shows that the proposed system dynamics model can support a more effective and enhanced view about small household appliances' waste management and fuzzy cognitive mapping model shows that public campaign effect is a more effective campaign method compared to private sector campaign. Waste collection centers developed and supported by municipalities or government provide a more intensive and increased recovery option, while it decreases landfill and incineration rate. In the model, several factors have been considered in order that recycled products can be added to production line according to the target of Turkey.

The system dynamics model at this point suggests also that campaign effects and company effects are outstandingly important in order to bring wastes to waste centers and to inform public or increase public awareness about recycling when the system works without any errors. The model also calculates how many of small household appliances in Turkey will be in process of recycling in order to reach the target of Turkey by 2018. In fuzzy cognitive mapping approach, it is concluded that government or municipalities should mainly support people to recycle the small household appliances instead of the fact that government or municipalities sell or give old appliances to private white good brands. It is more efficient that government or municipalities build recycling factories and apply campaigns. Company campaigns effects can only be a supportive approach.

In this study real data for the proposed system is limitedly used, because of lack of data, but main future targets have been put in the model. For future studies, real data should be used for all variables mentioned in the model in order to have more realistic approach.

\section{References}

Al-Khatib I.A., Eleyan D. and Garfield J. (2016), A system dynamics approach for hospital waste management in a city in a developing country: the case of Nablus, Palestine, Environmental Monitoring and Assessment, 188(9), 503.

Barnabè F. (2011), A "system dynamics-based balanced scorecard" to support strategic decision making, International Journal of Productivity and Performance Management, 60(5), 446-473. http://dx.doi.org/10.1108/ 17410401111140383.

Botha A., Grobler J. and Yadavalli V.S. (2017), System dynamics comparison of three inventory management models in an automotive parts supply chain, Journal of Transport and Supply Chain Management, 11(1), 1-12.

Buruzs A., Kóczy L.T. and Hatwágner M.F. (2014, November), Using Fuzzy Cognitive Maps approach to identify integrated waste management system characteristics, In Cognitive Infocommunications (CogInfoCom), 2014 5th IEEE Conference on (pp. 141-147). IEEE.

Çoban O., Seçme N.Y., Seçme G. and Özesmi U. (2006), An empirical analysis of firms' strategies in the turkish automobile market1, Economic and Business Review for Central and South - Eastern Europe, 8(2), 117-141.

Devi S.P., Rao K.S., Krishnaswamy S. and Wang S. (2010), System dynamics model for simulation of the dynamics of corneal transplants, Opsearch, 47(4), 284-292. http://dx.doi.org/ 10.1007/s12597-010-0023-0.

Forrester J.W. (1994), System dynamics, systems thinking, and soft OR, System Dynamics Review, 10, 245-256. doi:10.1002/ sdr.4260100211.

Ghisolfi V., Chaves G.D.L.D., Siman R.R. and Xavier L.H. (2017), System dynamics applied to closed loop supply chains of desktops and laptops in Brazil: A perspective for social inclusion of waste pickers, Waste Management, 60, 14-31.

Greasley A. (2005), Using system dynamics in a discrete-event simulation study of a manufacturing plant, International 
Journal of Operations \& Production Management, 25(5), 534-548. Retrieved from http://160.75.22.2/docview/ 232358137 ? accountid $=11638$.

Han J. and Morag C. (1995), The influence of the sigmoid function parameters on the speed of backpropagation learning, In Mira J. and Sandoval F. (eds.). From Natural to Artificial Neural Computation, Lecture Notes in Computer Science, 930, pp. 195-201. doi:10.1007/3-540-59497-3_175, ISBN 978-3-540-59497-0.

Hatwágner M.F., Buruzs A., Földesi P. and Kóczy L.T. (2014), Strategic decision support in waste management systems by state reduction in FCM models. In International Conference on Neural Information Processing, Springer, Cham, pp. 447457.

Kok K. (2009), The potential of Fuzzy Cognitive Maps for semiquantitative scenario development, with an example from Brazil, Global Environmental Change, 19(1), 122-133.

Konyalıoğlu A.K. and Bereketli Zafeirakopoulos i. (2018), “A System Dynamics Model for Small Household Appliances' Waste Management: A Case of Turkey", Protection and Restoration of the Environment XIV, PREXIV, Thessaloniki, Greece, pp. 411-417.

Kosko B. (1986), Fuzzy cognitive maps, International Journal of Man-Machine Studies, 24(1), 65-75.

Lee S., Han W. and Park Y. (2015), Measuring the functional dynamics of product-service system: A system dynamics approach, Computers \& Industrial Engineering, 80, 159. Retrieved from http://160.75.22.2/docview/1649225891? accountid=11638.

León M., Mkrtchyan L., Depaire B., Ruan D. and Vanhoof K. (2014), Learning and clustering of fuzzy cognitive maps for travel behaviour analysis, Knowledge and Information Systems, 39(2), 435-462.

Nair G.K. and Raj Rodrigues L.L. (2013), Dynamics of financial system: A system dynamics approach, International Journal of Economics and Financial Issues, 3(1), 14. Retrieved from http://160.75.22.2/docview/1266465919?accountid $=11638$.

Özesmi U. and Özesmi S.L. (2004), Ecological models based on people's knowledge: a multistep fuzzy cognitive approach, Ecological Modelling, 176, 43-64.

Öztürk T. (2015), Generation and management of electricalelectronic waste (e-waste) in Turkey, Journal of Material Cycles and Waste Management, 17(3), 411-421.
Papageorgiou E.I., Hatwágner M.F., Buruzs A. and Kóczy L.T. (2017), A concept reduction approach for fuzzy cognitive map models in decision making and management, Neurocomputing, 232, 16-33.

Papageorgiou E. and Kontogianni A. (2012), Using fuzzy cognitive mapping in environmental decision making and management: a methodological primer and an application, In International Perspectives on Global Environmental Change, IntechOpen.

Pariatamby A. and Victor D. (2013), Policy trends of e-waste management in asia. The Journal of Material Cycles and Waste Management, 15(4), 411-419.

Parsopoulos K.E., Papageorgiou E.I., Groumpos P.P. and Vrahatis M.N. (2003), A first study of fuzzy cognitive maps learning using particle swarm optimization, Proceedings of the IEEE, 1440-1447.

Pedamallu C., Ozdamar L., Ganesh L., Weber G. and Kropat E. (2010), A system dynamics model for improving primary education enrollment in a developing country, Organizacija, 43(3), 90, http://dx.doi.org/10.2478/v10051-010-0010-5.

Sinha-Khetriwal D., Kraeuchi P. and Schwaninger M. (2005), A comparison of electronic waste recycling in Switzerland and in India, Environmental Impact Assessment Review, 25(5), 492-504.

Stach W., Kurgan L., Pedrycz W. and Reformat M. (2005), Genetic learning of fuzzy cognitive maps, Fuzzy Sets and Systems, 153(3), 371-401.

Stylios C.D. and Groumpos P.P. (2004), Modeling complex systems using fuzzy cognitive maps, IEEE Transactions on Systems, Man, and Cybernetics-Part A: Systems and Humans, 34(1), 155-162.

Takiguchi H. (2016), Global Environment Facility's support for sustainable waste management, Journal of Material Cycles and Waste Management, 18(2), 248-257.

URL1: Atık Yönetimi Eylem Planı: 2008-2012. (2008, May), Retrieved from: http://www.cygm.gov.tr/cygm/files/ eylemplan/atikeylemplani.pdf.

URL2: Küçük Ev Aletleri Yeni Trendlerle Büyüyor. (2017, July 19), Retrieved from: http://www.gfk.com/en-gb/insights/pressrelease/kuecuek-ev-aletleri-yeni-trendlerle-bueyueyor/.

URL3: Resmi Gazete-Official Gazette (2012, May 22), Retrieved from: http://www.resmigazete.gov.tr/eskiler/2012/05/2012 0522-5.htm.

URL4: Anylogic simulation (2017, May 3), Retrieved from: https://www.anylogic.com/. 